Bond University

Research Repository

\title{
Hans J. Eysenck and Raymond B. Cattell on intelligence and personality
}

Boyle, Gregory J.; Stankov, Lazar; Martin, Nicholas G.; Petrides, K. V.; Eysenck, Michael W.; Ortet, Generos

Published in:

Personality and Individual Differences

DOI:

10.1016/j.paid.2016.04.029

Licence:

CC BY-NC-ND

Link to output in Bond University research repository.

Recommended citation(APA):

Boyle, G. J., Stankov, L., Martin, N. G., Petrides, K. V., Eysenck, M. W., \& Ortet, G. (2016). Hans J. Eysenck and Raymond B. Cattell on intelligence and personality. Personality and Individual Differences, 103, 40-47.

https://doi.org/10.1016/j.paid.2016.04.029

\section{General rights}

Copyright and moral rights for the publications made accessible in the public portal are retained by the authors and/or other copyright owners and it is a condition of accessing publications that users recognise and abide by the legal requirements associated with these rights.

For more information, or if you believe that this document breaches copyright, please contact the Bond University research repository coordinator. 


\title{
Hans J. Eysenck and Raymond B. Cattell on Intelligence and Personality
}

\author{
Gregory J. Boyle \\ Bond University \\ Gold Coast, Queensland \\ and \\ University of Melbourne \\ Parkville, Vic., Australia \\ Lazar Stankov \\ University of Sydney \\ Sydney, NSW, Australia \\ Nicholas G. Martin \\ QIMR Berghofer Medical Research Institute \\ Brisbane, Australia \\ K. V. Petrides \\ London Psychometric Laboratory \\ University College London, UK \\ Michael W. Eysenck \\ Roehampton University \\ London, UK \\ and \\ Generos Ortet \\ Universitat Jaume I de Castelló \\ Castellón, Spain
}




\begin{abstract}
The two most prominent individual differences researchers of the twentieth century were Hans J. Eysenck and Raymond B. Cattell. Both were giants of scientific psychology, each publishing scores of books and hundreds of empirical peer-reviewed journal articles. Influenced by Hebb’s distinction between physiological (Intelligence A) and experiential (Intelligence B), Eysenck focused on discovering the underlying biological substrata of intelligence. Analogously, Cattell proposed the Gf-Gc theory which distinguishes between fluid and crystallised intelligence. Cattell’s Culture Fair Intelligence Test (CFIT), a measure primarily of fluid intelligence, was constructed specifically to minimise differences in test bias in IQ scores between different ethnic/racial groups. Within the personality realm, Eysenck adopted a pragmatic three-factor model as measured via the Eysenck Personality Questionnaire (EPQ-R) and its variants. In contrast, Cattell employed a lexical approach that resulted in a large number of primary and secondary normal and abnormal personality trait dimensions, measured via the Sixteen Personality Factor Questionnaire (16PF), and the corresponding Clinical Analysis Questionnaire (CAQ), respectively. Recent molecular genetics findings provide empirical confirmation of Eysenck and Cattell's positions on the biological underpinnings of personality and ability traits, allowing an improved understanding of the causes of individual differences.
\end{abstract}

Keywords: Individual differences; Personality; Cognitive abilities; Gf-Gc theory; Culture Fair Intelligence Test; PEN model; EPQ-R; 16PF; CAQ. 
The study of personality and individual differences in the second half of the twentieth century was significantly influenced by two prominent figures: Hans J. Eysenck and Raymond B. Cattell. Both have their roots in British psychology. While Eysenck gained his PhD under Burt’s supervision at University College, London, Cattell earned his PhD at King's College, London under the supervision of Francis Aveling then President of the British Psychological Society. Both Eysenck and Cattell were key players in the movement to promote scientific psychology, as currently advocated expressly by the Association for Psychological Science. As Boyle (1998, "Remembering R. B. Cattell,” para. 2) stated,

Two of the greatest and most prolific contributors to the science of human personality during the 20th century were Professor Raymond B. Cattell, Ph.D., D.Sc., and Professor Hans J. Eysenck, Ph.D., D.Sc. While Cattell pursued his academic career in prestigious USA universities (Harvard, Clark, Illinois), Eysenck undertook his lifelong work at the Institute of Psychiatry, University of London. It is indeed ironic that the world would lose the two most eminent personality researchers within the space of only a few weeks. So prominent were these two men, that their work is now enshrined in the Cattellian and Eysenckian Schools of Psychology, respectively.

Both Eysenck and Cattell were ranked among the most highly cited psychologists of the twentieth century. Indeed, Eysenck was the most highly cited psychologist of his generation (Gray, 1997). Based on the peer-reviewed journal literature alone (Haggbloom et al., 2002, Table 1), Eysenck was the $3^{\text {rd }}$ most highly cited psychologist (after Freud, 
and Piaget, respectively), while Cattell was $7^{\text {th }}$ most highly cited. In relation to Cattell's impact on the field of psychology, Eysenck (1985, p. 76) remarked that,

Cattell has been one of the most prolific writers in psychology since Wilhelm Wundt...According to the Citation Index, he is one of the ten most cited psychologists, and this is true with regard to not only citations in social science journals but also those in science journals generally. Of the two hundred and fifty most cited scientists, only three psychologists made the grade, namely, Sigmund Freud in the first place, then the reviewer [H.J. Eysenck], and then Cattell. Thus there is no question that Cattell has made a tremendous impression on psychology and science in general.

Illustrative of the esteem in which these two giants of psychology were held by their peers, Buchanan (2010, p. 4) wrote about Eysenck, There can be little argument about the importance of Eysenck as an historical figure. His name ranks alongside American contemporaries such as Gordon Allport, B.F. Skinner, and Raymond Cattell...and he hardly had a rival on the UK scene...

Likewise, Horn (2001, p. 72) wrote about Cattell, The seven past-presidents of the American Psychological Association who selected him, despite his controversial writings, for a lifetime contributions' award were correct in their judgment. He must rank among the most important contributors to psychological science. 
Clearly, both Eysenck and Cattell have left their mark on the study of human intelligence and personality. Eysenck's contribution to the assessment of intelligence is augmented by his various attempts to discover its biological bases. Cattell will be remembered largely for his ideas about cognitive functioning and his theory of fluid and crystallised intelligence.

With respect to personality assessment, although Eysenck utilised both self-report measures and psychophysiological measures, Cattell systematically constructed measures of personality traits in different media of measurement - Life-Record including ratings of others (L-data); Questionnaire (Q-data); and Test (T-data). With regard to T-data, Cattell and Warburton (1967) compiled a list of over 2000 objective test measures of personality and motivation, and constructed the Objective-Analytic Test Battery (OAB) that measures 10 factor-analytically derived personality trait constructs - see Schuerger (2008).

It has often been assumed that Eysenck used his knowledge of psychopathology to derive theoretically-based "top-down" measures of personality traits, whereas Cattell relied on an atheoretical “bottom-up” lexical approach. However, Eysenck’s approach was not entirely theoretically driven. As Goldberg wrote to Eysenck (February 6, 1995; see van Kampen, 2009, p. 13),

It is not clear to the world at large how your PEN model is not well described as an example of the heuristic school, given that you explicitly adopted 'some psychiatric system of classification' for [Psychoticism and Neuroticism], and you used your own 'notion of what traits might be important' to select [Extraversion]. 
Nevertheless, Eysenck’s pragmatic approach clearly contrasted with Cattell’s emphasis on the empirical lexical approach. Accordingly, the measures and theories of personality structure that resulted from their respective factor-analytic studies emerged with some distinct differences. Boyle (1998, “Remembering R. B. Cattell,” para. 2) pointed out that,

Critics of the psychology of individual differences have often claimed naively that the use of factor analysis in test construction has 'only led to confusion -- since Eysenck found three factors, while Cattell found 16 factors' within the personality domain. Yet ... Eysenck and Cattell were talking about personality measurement at different levels within the hierarchical trait model. Cattell concentrated on primary factors, while Eysenck focused on broader secondary dimensions. Indeed, at the second-order 16PF level, the degree of communality between the Eysenckian and Cattellian factors was striking!

Clearly, Eysenck and Cattell's contributions to the delineation of personality structure were compatible. As Eysenck (1984, p. 336) himself stated, The Cattell and Eysenck constructs and theories should be seen, not as mutually contradictory, but as complementary and mutually supportive.

On the other hand, Cattell was not so willing to readily accept the compatibility between his and Eysenck’s approaches. According to Cattell (1986, p. 153), 
Eysenck's resort to 3 factors is shown to be theoretically faulty and unable to equal the criterion predictions obtainable from the 16PF primaries.

Indeed, the empirical evidence does support Cattell's argument about the greater predictive variance obtainable from a larger number of primary factors than from a smaller number of broad secondary factors (Mershon \& Gorsuch, 1988).

Eysenck and Cattell investigated individual differences using the hypotheticodeductive method (or inductive-hypothetico-deductive method - Cattell, 1978). In other words, Eysenck attached considerable importance to theoretically-driven research, whereas Cattell was much more skeptical about theory preceding empirical evidence. Although, historically, there had been a gap between differential and experimental psychology (Cronbach, 1957), Eysenck (1997a) explicitly combined both experimental and correlational approaches, while Cattell was at the forefront in promoting multivariate experimental research (Cattell, 1966a; Nesselroade \& Cattell, 1988).

Both Eysenck and Cattell subscribed to the prevailing positivist paradigm and to the nomothetic approach (e.g., Allport, 1937; Cattell, 1973; Eysenck, 1954; Piekkola, 2011). It is worth examining this predilection in some detail if only because committing one's research program to a particular paradigm inevitably alienates it from other paradigms. The twofold temptation may then arise to turn a blind eye to the limitations of the chosen paradigm and to attempt to disparage alternatives (cf. Eysenck, 1986). Yet, Eysenck’s critique of non-positivist approaches such as psychoanalysis (Eysenck, 1952), contrasted with his willingness to entertain other controversial topics, such as parapsychology (Eysenck, 1982b) and astrology (Eysenck \& Nias, 1982). Presumably, 
one of the reasons for Eysenck's dislike of psychodynamic psychology was that its tenets could not easily be put to the empirical test (see Kline, 1972), whereas Eysenck considered that valid experiments could be carried out to test parapsychological and astrological predictions.

However, the chasm between nomothetic and idiographic approaches is not conducive for a holistic psychology with the individual person as its main focus. The tendency of trait psychologists to align with nomothetic approaches, which they equate with 'scientific,' and to distance themselves from idiographic approaches, which they equate with 'unscientific,' is problematic for at least two reasons. Firstly, it vastly underestimates the ineradicable contributions of giants of psychology, such as Freud, Jung, Maslow, and Piaget, who worked mostly within the idiographic tradition. Secondly, and perhaps more importantly, the uncritical overreliance on nomothetic approaches, as typically applied in mainstream personality psychology, has brought about a "triumph of the aggregate” (Danziger, 1990) that is threatening to establish a personality psychology devoid of the person.

Cattell and Eysenck worked at a time when the foundations of contemporary academic psychology as we know it were being laid. They spearheaded the movement towards a quantitative psychology, which they perceived as equivalent to a scientific psychology and which eventually became the dominant paradigm. Their key ideas for a scientific (meaning positivist) psychology, were enthusiastically shared by many others, and gradually became central to individual differences research, specifically, and to academic psychology, more generally. 
How much of this influence actually originated with Cattell and Eysenck and how much merely reflected the zeitgeist of the time is difficult to tell. In the 1950s and 1960s when the two personality psychologists became established, psychology was characterized by a nervousness to imitate the apparent success of the natural sciences, which had blithely espoused a philosophy of materialism (Sheldrake, 2013; Whitehead, 1925/2011). This caused an unrestrained import of methods, concepts, and technologies from the natural sciences at the expense of methodologies that are prima facie more compatible with a psychology of the individual person (e.g., Stern, 1911), such as introspection and psychoanalysis.

Cattell and Eysenck were key players in the movement to emulate the natural sciences even though many natural scientists seemed loath to consent to such advances. Yet the question of whether the methodologies of the natural sciences are appropriate for the investigation of psychological phenomena has always loomed large (e.g., Bickhard, 1992; Snygg, 1955).

The dominant paradigm in personality research - differential psychology - has not grappled well with challenges such that knowledge about individual differences is not the same as knowledge about individuals, that individual behaviour cannot be explained in terms of differences between individuals (Lamiell, 1997), that ordinal measures are not necessarily quantitative (Michell, 2009), and that psychometrics lacks valid units of measurement (Kline, 1997). It has been all too easy for differential psychology to "sweep these issues under the carpet”.

Despite these caveats, here we outline some of the many contributions of these two important figures to the field of individual differences and point to some areas of 
contemporary research influenced by their work. We also mention a couple of events that brought both Eysenck and Cattell into the limelight within the broader community, as well as re-examining new evidence from molecular genetics that provides vindication for Eysenck and Cattell's focus on the biological basis of complex trait dimensions.

\section{Eysenck on Intelligence and its Biological Substrata}

Eysenck was from the 'London School’ of psychology with its lineage of Galton, Spearman, and Burt. Eysenck’s hypothesis was that general intelligence (g) is underlain by mental speed, which he tested through various response and inspection time protocols aided by complex algorithms (e.g., Barrett, Petrides \& Eysenck, 1998). Within the experimental psychology paradigm, Eysenck strongly advocated a theoretical and laboratory-based approach for intelligence research (Eysenck, 1967a).

In the 1960s, Guilford's Structure of the Intellect (SOI) model became popular although Eysenck previously had similar ideas (Eysenck, 1971). In Eysenck’s model one dimension corresponded to content (verbal, numerical, and spatial), the other to mental processes (reasoning, memory, and perception). The third dimension was “quality” which refers to the nature of test administration - the distinction between 'speeded' and 'power' tests. However, neither Guilford’s nor Eysenck’s models of ability structure have survived the test of time, and subsequent studies with psychometric tests of intelligence have not derived factors corresponding to either model (see critique of SOI model Brody \& Brody, 1976, pp. 43-57).

The biological underpinnings of intelligence depend on genetic potential expressed through developmental and neurochemical pathways (Eysenck, 1982, 1998). Biological correlates of intelligence can be found in measurements from the 
electroencephalogram (EEG), averaged evoked potential (AEP), contingent negative variation (CNV), galvanic skin response (GSR), reaction time (RT) and other methods including functional magnetic resonance imaging (fMRI).

Psychometric intelligence is measured by IQ tests. While related to biological intelligence, it is also influenced by cultural and experiential factors, family upbringing, socio-economic status, education, and the like. Approximately $30-40 \%$ of the total variance is accounted for by non-genetic influences (Deary, 2000). The relative importance of genetic and environmental influences on psychometric intelligence varies as a function of age: genetic factors account for approximately $20 \%$ of individual differences in intelligence in infancy but 80\% in later adulthood (Plomin \& Deary, 2015).

Finally, there is social intelligence (practical intelligence) - the application of intelligence in everyday social life and work (Sternberg et al., 2000). Social intelligence involves factors additional to psychometric intelligence. For example, even if an individual has high IQ but is an alcoholic, is mentally or physically ill, has poor education, and/or has low motivation/drive, it is unlikely that s/he will be a high achiever.

Evidently, much of Eysenck's empirical work was reductionist in linking intelligence to its biological substrata. Although Eysenck employed several measures, the bulk of his work focused on mental speed and EEG measures.

Mental Speed. Eysenck’s (1967a) article, which examined Galton’s hypothesis about the close link between mental speed and intelligence, proved to be quite influential and timely. His article promoted the ideas which he had developed in collaboration with Furneaux, who had published a paper in a book edited by Eysenck (1960), while an equally important work by Eysenck’s student (P. O. White), subsequently appeared in 
another book (Eysenck, 1973). All these works assumed three components of intelligence: speed and two aspects of personality labelled as persistency (tendency to invest effort when the solution is not easy) and error checking (tendency to check the answer to an item prior to registering it).

Eysenck’s suggestion to investigate mental speed fell on a fertile ground. In the 1960s, a revitalised cognitive psychology began to employ RT measures. Its usefulness was demonstrated in Saul Sternberg's studies of memory search. The advent of microcomputers subsequently facilitated precise measurements of timed performance. While Eysenck was only marginally interested in new developments in experimental cognitive psychology, his plea to examine Galton’s ideas was taken seriously by others. In several studies, Jensen (1982) demonstrated that both simple RT and choice RT correlate about 0.20 to 0.30 with psychometric measures of intelligence. However, the relationship between IQ and mental speed is insufficiently strong to indicate that it might lead to a comprehensive understanding of the biological underpinnings of intelligence.

Initially, Eysenck viewed more intelligent people as having faster thinking, information transmission and processing. Jensen also subscribed to this notion, but believed that mental speed is important because of the role of working memory in thinking. Since information in working memory fades quickly, people with higher intelligence and faster mental speed can perform more operations in a limited timespan than those with slower processing speed.

Towards the end of his life, Eysenck modified his account of the relationship between mental speed and intelligence due to finding notable correlations between intelligence test (IQ) scores and measures of variability in RT. Over the many trials 
needed for reliable RT measurement, some individuals show considerable instability from trial to trial, although more intelligent individuals generally show relatively small variability. Eysenck proposed that less intelligent individuals transmit information less efficiently with a greater probability of errors occurring. However, the finding of high correlations between measures of mental speed and measures of variability of speed calls for a single rather than two distinct mechanisms (i.e., speed and probability of synaptic error) to explain the observed phenomena. Roberts and Stankov (1999) showed that mental speed measures define several distinct factors, such that mental speed is not the basic process of intelligence. An alternative capacity view that emphasises the role of attention and working memory instead of speed in intelligence has also gathered support (Stankov, Boyle \& Cattell, 1995).

Electroencephalography and intelligence. Towards the end of the 1960s, Eysenck started using a more direct (psychophysiological) measure of biological intelligence - the EEG. Two methods were employed. In the first, the EEG was recorded while the individual was in a resting position. Significant but relatively small correlations (comparable to those reported with RT) were obtained between measures of intelligence and EEG parameters. In the second method, the person was again resting but a light (or a tone) was presented at certain time intervals. The light evokes a change in the EEG records which are averaged over many trials to obtain the "average evoked potential” (AEP). In Eysenck's studies, various AEP measures were correlated with intelligence test scores. Eysenck with his students, Hendrickson and Hendrickson (1980), developed a new AEP measure reflecting the signal complexity (extent of small departures from the smooth AEP recording). Eysenck proposed that the differences in complexity of AEP 
recordings (like RTs) are related to the transmission of signals over the synapses within the central nervous system. In his autobiography, Eysenck reported correlations between 0.30 and 0.40 in a study undertaken with children (Eysenck, 1997b). While failures to replicate Hendrickson and Hendrickson's findings initially were thought to be due to subtle differences in methodology used across different laboratories (Barrett \& Eysenck, 1992a), there were also failures to replicate within the same institution from which the original findings had been obtained (Barrett \& Eysenck, 1992b).

Some AEP studies point to another way that speed may be important for intelligence. Using fast Gamma waves, Stankov et al. (2006) correlated the speed of synchronisation (or “tuning-in”) between different brain regions involved in processing a particular stimulus. Following Hebb (1949), it was expected that individuals with higher intelligence test scores would show faster activation of distinct brain regions involved in a particular cognitive activity. High correlations between IQ scores and speed of synchronization were indeed found (Stankov et al., 2006). While a recent meta-analysis (Basten, Hilger \& Fiebach, 2015) found little evidence that high intelligence is associated with greater neural efficiency, it did provide convincing evidence that integration of frontal and parietal brain regions is greater among highly intelligent individuals.

\section{Cattell and Non-cognitive Correlates of Intelligence}

While Eysenck’s work on intelligence was influenced by Hebb (1949) who postulated the existence of Intelligence A (physiological), and Intelligence B (experiential), Cattell’s Gf-Gc theory (Cattell, 1963; Horn \& Cattell, 1966) analogously distinguished between fluid intelligence (Gf) - (broad ability to reason, form concepts, and solve problems using unfamiliar information or novel procedures) and crystallised 
intelligence (Gc) - (the ability to reason using previously learned knowledge or procedures) - (see Brody \& Brody, 1976). Subsequent empirical work led to the identification of several additional broad cognitive factors including quantitative ability (Gq), reading and writing ability (Grw), short-term memory (Gsm), long-term storage and retrieval (Glr), visual processing (Gv), auditory processing (Ga), processing speed (Gs) and decision/RT speed (Gt) - now known as the Cattell-Horn-Carroll (CHC) theory of intelligence (see Schneider \& McGrew, 2012).

Cattell (with wife Karen) founded the Institute for Personality and Ability Testing (IPAT), which produced many psychometric tests of intelligence and cognitive abilities, including the historic Culture Fair Intelligence Test (CFIT), and the Comprehensive Ability Battery (CAB), among others (see Cattell \& Johnson, 1986).

Cattell (1987) was interested in processes that led to the emergence of crystallised from fluid intelligence. Cattell's Investment theory posits that individual differences observed in the development of skills and knowledge (Gc) are partially attributed to the “investment” of Gf in various aspects of the learning process. Investment theory also suggests that non-cognitive traits and dispositions including interests, motivation and personality all affect cognitive abilities. This set up the stage for exploring links between cognitive and non-cognitive processes. One extension was the Process, Personality, Intelligence and Knowledge (PPIK) theory (Ackerman, 1996) which elaborates on Cattell's original ideas. Another extension derives from the efforts of educationists to identify the best non-cognitive predictors of achievement and intelligence. From among the many non-cognitive variables considered, those related to self-beliefs (i.e., confidence, self-efficacy and anxiety) proved to be the most important (Stankov, 2013). 


\section{Measurement of Personality}

Eysenck aimed to place personality trait factors within a psychobiological network of constructs (Eysenck, 1967b), dictating his preference for interpreting somewhat crude unrotated centroid factors, in contrast to Cattell who employed optimal factor analytic procedures and rotated factors to maximum simple structure (Cattell, 1978). Cattell pioneered some of the now standard factor-analytic techniques such as the Scree test (Cattell, 1962, 1966b). However, aiming for definitional precision, Cattell labelled his factors idiosyncratically, thereby inadvertently distancing his work from mainstream psychology.

As indicated earlier, the early stages of Eysenck's attempts to describe personality were by no means entirely "top-down” or theory-driven. He was influenced by earlier theorists (e.g., Jung) and by previously devised questionnaires (see Eysenck \& M. Eysenck, 1985). The Maudsley Personality Inventory (MPI) included several items to assess extraversion that were similar to items previously used by Guilford. The three broad factors Eysenck identified - Extraversion, Neuroticism, and Psychoticism - became the focus of an international research program (e.g., see Barrett, Petrides, S. Eysenck \& Eysenck, 1998).

Eysenck constructed numerous personality measures, among which the Eysenck Personality Questionnaire, in its various forms is the most widely recognised (Eysenck, Eysenck \& Barrett, 1985). Furnham, S. Eysenck, and Saklofske (2008) provided reasons why many of Eysenck's measures remain in use today: (1) they focus on broad factors that can be easily integrated into wider nomological networks; (2) they strive to reach beyond mere descriptions to provide actual explanations of processes; (3) they have been 
validated in many empirical studies; (4) they have been widely applied across different disciplines; and (5) they have undergone continued rectification. Eysenck's self-report questionnaires include the Maudsley Medical Questionnaire (MMQ), the Maudsley Personality Inventory (MPI), the Eysenck Personality Inventory (EPI), the Eysenck Personality Questionnaire (EPQ), the Eysenck Personality Questionnaire - Revised (EPQ-R), the shorted form (EPQ-R-S), and the Eysenck Personality Profiler (EPP). While Eysenck focused on broad personality trait dimensions - Extraversion, Neuroticism and Psychoticism, Cattell focused on primary trait dimensions, although at the 16PF second-order level, five broad personality factors were labelled Extraversion, Anxiety/Neuroticism, Tough Poise, Independence, and Control, respectively (H. Cattell \& Mead, 2008; Krug \& Johns, 1986). The first two line up with Eysenck’s Extraversion and Neuroticism factors, and the corresponding Big Five dimensions (Goldberg, 1993; Saucier, 2008). Yet, both Eysenck (1992a) and Cattell (1995) had severely criticised the Big Five model (see Boyle, 1989, 2008) which accounts for less than $60 \%$ of the variance in the normal trait sphere alone (Boyle, Stankov \& Cattell, 1995, p. 432; Boyle, 2008, p. 298).

Aside from producing psychometric measures of intelligence, IPAT also generated many personality instruments and their downward extensions including the Sixteen Personality Factor Questionnaire (16PF, HSPQ, ESPQ); the Clinical Analysis Questionnaire (CAQ) - providing measures of 12 abnormal personality traits in addition to the 16PF factors; the Objective-Analytic Test Battery (OAB) - 10 objective tests of personality trait constructs; the Motivation Analysis Test (MAT, SMAT, CMAT) - an objective test of 10 dynamic motivational trait constructs; the Eight State Questionnaire 
(8SQ) - which measures eight clinically important emotional/mood states. The $16 \mathrm{PF}$ is a widely used measure of normal personality traits which has been adapted for use in numerous languages (Boyle \& Barton, 2008).

One important difference between the Cattell and Eysenck models of personality is related to the conceptualisation and measurement of Psychoticism. Using factor analytic methodology, Cattell constructed the multidimensional CAQ (revised as the Psychological Evaluation Personality Questionnaire or PEPQ) - (see Krug, 2008). In contrast, Eysenck focused on a single broad abnormal personality factor - Psychoticism as measured in the EPQ and EPQ-R instruments.

The question of what the Psychoticism scale really measures (Eysenck, 1992b; Eysenck, Eysenck \& Barrett, 1985; Ortet et al., 1999) remains controversial. Its score distribution shows positive skewness, and lower item homogeneity (the scale is composed of relatively unrelated traits) than either the Extraversion or Neuroticism scales. Indeed, one of the present authors (GJB) in a brief visit with Eysenck at the Institute of Psychiatry in 1988 argued that measurement of a single Psychoticism trait seemed problematic given the occurrence of distinctly different forms of psychotic illness, and the fact that Cattell had empirically delineated 12 separate abnormal trait factors. Despite these arguments, Eysenck maintained his position that Psychoticism was a unidimensional factor.

Ibáñez, Ortet and Moro (2000) compared the bias of different Spanish versions of the Psychoticism scale. As expected from Cattell's work with the CAQ, factor analyses of the Psychoticism, Extraversion and Neuroticism scales of the EPQ-R indicated a larger heterogeneity of the Psychoticism scale as compared with the other two scales. When 
more socially acceptable Psychoticism items are included, there is a slight reduction in scale bias. However, despite Eysenck's assurances as to the validity of the Psychoticism scale, conceptual and psychometric issues remain unresolved (M. Eysenck, 2016).

Eysenck’s research into personality and coping (see Marqués et al., 2005), and his research into cancer and coronary heart disease enriched health psychology, generating extensive debate, and quite often controversies, such as his finding of multiple synergistic causal factors in smoking-related illnesses (e.g., Eysenck, 1991a). As with other topics he researched, and while certain detractors have questioned Eysenck's objectivity in his research into personality, stress and physical disease using Grossarth-Maticek’s rather unwieldy epidemiological data sets, the fact is that remaining true to character, Eysenck always carefully and logically considered the empirical evidence in attempting to solve controversial issues and advance psychology as a science (e.g., see Eysenck, 1991b, 1993). After carefully considering all the disparaging criticisms and the likely impact on the outcomes obtained, Eysenck, 1993, p. 73) concluded that,

The Grossarth-Maticek data are genuine - even though at times marred by errors that fortunately make no difference to the overall conclusions.

Rather than somewhat pedantic, unending criticism, and in order to settle the controversy once and for all, detractors would do well to undertake independent replication studies on multiple large samples to ascertain the veracity or otherwise of Eysenck and Grossarth-Maticek’s findings.

The impact of Eysenck and Cattell's work is readily apparent in contemporary research programs, such as that of trait emotional intelligence, where we can witness the 
use of factor analysis for conceptualisation (Petrides, Pita \& Kokkinaki, 2007) and the investigation of constructs from multiple perspectives (Petrides et al., 2016). While there are many measures of emotional intelligence, most consist, in part, of a combination of low neuroticism and high extraversion (Matthews, Zeidner \& Roberts, 2004). However, such research programs represent a continuation of Eysenck's and Cattell's loftiest ideals, and aim to integrate the research approaches that both these pioneers advocated.

\section{Controversies that Spilled beyond Academic Psychology}

The views of both Eysenck and Cattell particularly in relation to their scientific curiosity about ethnic differences in intelligence test scores or their speculations about eugenics have been maligned by certain ill-informed critics. As it frequently happens, the media and broader community were interested in sensationalism and controversies. Here, we mention two that were linked to the issues of genetic heritability and intelligence.

\section{Disruption of Eysenck's Talks at Melbourne University and Sydney University}

In 1977 Hans Eysenck and Arthur Jensen were invited to give talks at several Universities in Australia. Jensen discussed the relationship between intelligence and learning while Eysenck’s focus was on intelligence and behaviour therapy. At the closure of the “hippy era," these authors were often misperceived as “academic racists”. Their first stopover was in Melbourne and from media reports it became clear that demonstrations protesting their positions were both relatively large and well-organised. Australian media reported that the speakers were physically assaulted and pelted with tomatoes and eggs by noisy protesters at the University of Melbourne, making it virtually impossible for either researcher to deliver their addresses. The next stopover was at the University of Sydney where Eysenck was scheduled to give two public lectures. At the 
first talk, protestors who had gained entry into the lecture theatre were abusive and shouted many derogatory remarks, and while a water bomb hit the professor who was to introduce Eysenck to the audience, this time there was no physical attack on Eysenck himself. Nevertheless, the talk was cancelled due to the unruly crowd. Security arrangements for the second talk were increased but almost nothing could be heard due to the noise produced by demonstrators at the door. It was remarkable to see Eysenck keep his composure and behave in a dignified way in the face of such disruptive behaviour. For the second talk, one of the present authors (LS) organised a group of postgraduate students and tutors with the intention of helping the NSW police in defending Eysenck against violent physical attacks. When, 20 years later, the news of Hans Eysenck's death reached Australia, the University of Sydney showed a film depicting the 1977 event and the audience in attendance in 1997 wholeheartedly agreed that the accusations of academic racism levelled against Eysenck were unwarranted and misplaced.

\section{Withholding of Cattell's APF Gold Medal Award}

While both Eysenck and Cattell were prodigious researchers and scholars, Goldberg (1968, p. 618) had described Cattell as "Psychology’s Master Strategist”. In recognition of Cattell's monumental contributions to psychological science spanning more than seven decades, the American Psychological Foundation (comprising no fewer than seven past APA presidents) identified Cattell as the 1997 recipient of psychology's most prestigious Gold Medal Award for Lifetime Achievement in Psychological Science. The official citation read as follows:

In a remarkable 70-year career Raymond B. Cattell has made prodigious, landmark contributions to psychology, including factor 
analytic mapping of the domains of personality, motivation, and abilities; exploration of three different media of assessment; separation of fluid and crystallized intelligence; and numerous methodological innovations. Thus, Cattell became recognized in numerous substantive areas, providing a model of the complete psychologist in an age of specialization. It may be said that Cattell stands without peer in his creation of a unified theory of individual differences integrating intellectual, temperamental, and dynamic domains of personality in the context of environmental and heredity influences. (American Psychologist, 1997, p. 797)

However, in a "last minute" political attack, Cattell at 92 years of age and frail, was accused of academic racism, leading to the withdrawal of this final prestigious honour, despite his having stated unambiguously more than a decade earlier that, The only reasonable thing is to be noncommittal on the race question - that's not the central issue, and it would be a great mistake to be sidetracked into all the emotional upsets that go on in discussions of racial differences. We should be quite careful to dissociate eugenics from it - eugenics' real concern should be with individual differences. (Cattell, 1984, “Interview with R. B. Cattell,” para. 18)

In analysing the unsolicited, derogatory accusations that resulted in the withholding of Cattell’s APF Gold Medal Award, Lotz (2008) concluded that, 
Cattell was deliberately misquoted...and labelled as an academic racist. The views he developed in the 1930s were common among his contemporaries when beliefs in racial differences were widely held, and should not be distorted by judgment according to today's standards. General scientific observations should not be read as personal moral statements. He was particularly wronged during the 1990s by certain writers (William H. Tucker and Barry Mehler) who picked out certain references referring to Germany, Hitler or genocide and quoted them out of context. (p. 136)

Thus, despite their monumental contributions to scientific psychology, both Eysenck and Cattell's work involving the empirical measurement of intelligence in various cultural groups was deliberately maligned, resulting, for example, in the wrongful withholding of Cattell's APF Gold Medal Award. In direct contrast to the derogatory accusations of such politicallymotivated detractors, Cattell (1940) had specifically constructed the Culture Fair Intelligence Test (CFIT) in order to minimise differences in IQ scores across different ethnic groups.As Richard Gorsuch wrote in his letter to the American Psychological Foundation,

The charge of racism is 180 degrees off track. [Cattell] was the first one to challenge the racial bias in tests and to attempt to reduce that problem.” (Gorsuch, 1997, "Letter to the American Psychological Foundation,” para. 4). 
Likewise, Eysenck was vehemently opposed to racist ideology and racism. As Eysenck (1997b, p. 40) specifically stated,

My hatred of Hitler and the Nazis, and all they stood for, was so overwhelming that no argument could counter it.

In collaborating in a professional capacity on research projects with either Hans Eysenck and/or Raymond Cattell over many years (and in some instances decades), the present authors can attest absolutely that neither Eysenck nor Cattell ever advocated racism, despite the ostensibly untoward asseverations of detractors, seemingly trying to "make a name for themselves" by denigrating and besmirching these two giants of twentieth century empirical psychology.

\section{New Developments - Vindication of Eysenck and Cattell's Views on the Biological Basis of Traits}

Recent developments in the molecular genetics of complex traits have lent new support to the emphasis that both Eysenck and Cattell placed on the importance of genetic factors underlying individual differences in both intelligence and personality. The evidence in their day came entirely from results of family, adoption, and particularly twin studies, all of which were subjected to fierce criticisms by detractors.

From about 1990, researchers started to go beyond estimating heritability (the proportion of total variation due to genetic causes) in the attempt to identify the actual genes causing variations in behaviour. Two approaches were tried. First, candidate gene studies, in which the researcher guessed what sort of genes might be involved, genotyped 
them in phenotyped samples and tested for association. The second approach was genetic linkage analysis which is hypothesis free, being agnostic as to which particular genes are involved, and entails testing for co-segregation within families of a trait with markers typed at regular intervals across all chromosomes. In principle, linkage analysis should detect any contributing gene signal, but in practice, impossibly large sample sizes are required to do so reliably, except for traits that are almost monogenic, like blue-brown eye colour. The abject failure of these two methods left the field despondent and puzzled, but provided the first glimmerings of just how small gene effects on complex traits might be, and provided the rationale for the only method that could detect them.

Risch and Merikangas (1996) proposed that genes causing variation in complex traits like behaviour and common diseases could be found by a genome-wide association scan (GWAS) that entailed typing genetic markers called single nucleotide polymorphisms (SNPs) at high density right across the human genome and testing for association with each and every one of them (cf. Berg, van den et al., 2014). It took almost another decade before the technology to enable this became widely available, in the form of "SNP chips" - microarrays that could type initially 10,000 SNPs, then 100,000, and eventually a million or more markers. The very first success with the GWAS technique was for age related macular degeneration (AMD) the most common form of blindness in old people (Hoh \& Ott, 2003; Klein et al., 2005), and obtained with a sample of only 96 cases with severe AMD and 50 controls. This gave the impression that finding complex trait genes would be easy, but subsequent success required much larger samples because the causal genes had small effects. For height, a trait with about the same heritability as IQ (0.80), it was only when the GWAS sample size got to around 
14,000 cases that genes began to be identified, but with more than 300,000 individuals now genotyped, around 700 genes have been identified as affecting adult height.

While we still do not have genotyped samples that large for intelligence (IQ), we do have very large samples phenotyped for educational attainment since this is a standard socio-demographic covariate collected in many biomedical and behavioural studies.

Educational attainment (scored as number of years of schooling or simply as the binary yes/no variable "Did you go to college?” (in the north American sense) correlates with psychometric IQ scores about 0.5 and can be regarded as a proxy - the imperfect correlation being compensated for by the much larger sample sizes available for educational attainment.

The first GWAS study of educational attainment $(\mathrm{N}=126,000)$ identified a number of associated SNPs (Rietveld et al., 2013). An expanded replication study with $(\mathrm{N}=305,000)$ - (Rietveld et al., 2014) found more than 70 significant SNPs for educational attainment and a high genetic correlation with IQ scores $(\mathrm{rG}=.70)$. Interestingly it also showed a genetic correlation with intracranial volume of 0.23 , confirming one of Eysenck's prognostications on the biological basis of intelligence. Perhaps most interesting was the strong negative genetic correlation with Neuroticism $(\mathrm{rG}=-0.41)$ highlighting that in addition to high IQ, emotional stability also contributes positively to high educational attainment.

Although individual SNPs may contribute only slightly to the variance in educational attainment, it is the cumulative effect of multiple SNPs which has greater predictive influence. As Domingue et al. (2015, p. 2) commented, 
The individual genetic variants discovered exhibited only very small effects on educational attainment, consistent with findings from GWASs of other complex traits ranging from body mass index to schizophrenia. But the results of the GWAS are not limited to the handful of SNPs identified. It is possible to combine information from all of the SNPs analysed in the GWAS to calculate a "polygenic score" that summarizes genome-wide genetic predisposition to educational attainment.

Until recently, less progress had been made unravelling the genes behind personality traits. However, a large international Genetics of Personality Consortium with collectively 63,661 participants from 29 discovery cohorts and 9,786 participants from a replication cohort measured for Neuroticism and Extraversion found a genome-wide significant SNP for Neuroticism (de Moor et al., 2015) in both the discovery metaanalysis, and in the meta-analysis of all 30 cohorts. As de Moor et al. (p. 642) stated, Common genetic variants explain 15\% of the variance in neuroticism. Polygenic scores based on the meta-analysis of neuroticism in 27 cohorts significantly predicted neuroticism...in the 2 other cohorts... neuroticism is influenced by many genetic variants of small effect that are either common or tagged by common variants.

In regard to detecting underlying causal genes for Extraversion, van den Berg et al. (2015, Abstract) in a large GWAS meta-analysis based on a combined sample $(\mathrm{N}=$ 63,030) reported that, 
Extraversion is a highly polygenic personality trait, with an architecture possibly different from other complex human traits, including other personality traits. Future studies are required to further determine which genetic variants, by what modes of gene action, constitute the heritable nature of extraversion.

Breaking news from the UK Biobank $(\mathrm{N}=91,000)$, all measured with the 12-item short-form of the Eysenck Neuroticism scale and typed on a single chip in a single laboratory, has finally produced a breakthrough with one very large hit and around eight smaller ones for Neuroticism. Congruent with Eysenck's rationale of Neuroticism as the trait underlying clinical depression, the genetic correlation between the two has been measured at $\mathrm{rG}=.64$.

\section{Summary}

Eysenck's tireless efforts to improve the measurement of the biological correlates of personality and intelligence have led to a better understanding of the causes of individual differences. Likewise, Cattell's exhaustive efforts to map out a factoranalytically derived taxonomy of personality and ability traits has greatly enhanced our understanding of such constructs. With recent discoveries of specific genetic markers (SNPs), we can see that both Eysenck and Cattell's scientific interest and emphasis on the biological basis of individual differences in human personality and cognition are now finding confirmation in the modern era of molecular genetics and big science. What better vindication of one's scientific programme/heuristic could any dedicated scientist wish for? 


\section{References}

Ackerman, P. L. (1996). Intelligence as process and knowledge: an integration for adult development and application. In W. A. Rogers, A. D. Fisk \& N. Walker (Eds.), Aging and Skilled Performance: Advances in Theory and Applications. Hillsdale, NJ: Erlbaum.

Allport, G. W. (1937). Personality: A Psychological Interpretation. New York: Henry Holt.

American Psychological Foundation Gold Medal Award for Life Achievement in Psychological Science. (August, 1997). American Psychologist, 52, 797-799.

Barrett, P. T. \& Eysenck, H. J. (1992a). Brain electrical potentials and intelligence. In A. Gale \& M. W. Eysenck (Eds.), The Handbook of Individual Differences: Biological Perspectives, Vol. 3 (pp. 255-285). New York: Wiley.

Barrett, P. T. \& Eysenck, H. J. (1992b). Brain evoked potentials and intelligence: the Hendrickson paradigm. Intelligence, 16, 361-382.

Barrett, P. T., Petrides, K. V. \& Eysenck, H. J. (1998). Estimating inspection time: response probabilities, the BRAT IT algorithm, and IQ correlations. Personality and Individual Differences, 24, 405-419.

Barrett, P. T., Petrides, K. V., Eysenck, S. B. G. \& Eysenck, H. J. (1998). The Eysenck Personality Questionnaire: an examination of the factorial similarity of P, E, N, and L across 34 countries. Personality and Individual Differences, 25, 805-819.

Basten, U., Hilger, K. \& Fiebach, C. J. (2015). Where smart brains are different: a quantitative meta-analysis of functional and structural brain-imaging studies on intelligence. Intelligence, 51, 10-27. 
Bickhard, M. H. (1992). Myths of science: misconceptions of science in contemporary psychology. Theory and Psychology, 2, 321-337.

Boyle, G. J. (1988). Contribution of Cattellian psychometrics to the elucidation of human intellectual structure. Multivariate Experimental Clinical Research, 8, 267-273.

Boyle, G. J. (1989). Re-examination of the major personality type factors in the Cattell, Comrey, and Eysenck scales: were the factor solutions by Noller et al. optimal? Personality and Individual Differences, 10, 1289-1299.

Boyle, G. J. (1998). In R. G. G. Cattell (Ed.), Remembering Raymond Bernard Cattell. http://www.cattell.net/devon/rbcpers.htm\#Greg\%20Boyle (Retrieved 7 December, 2015)

Boyle, G. J. (2008). Critique of Five-Factor Model (FFM). In G. J. Boyle, G. Matthews \& D. H. Saklofske (Eds.), The SAGE Handbook of Personality Theory and Assessment: Vol. 1 - Personality Theories and Models (pp. 295312). Los Angeles, CA: Sage.

Boyle, G. J. \& Barton, K. (2008). Contribution of Cattellian personality instruments. In G. J. Boyle, G. Matthews \& D. H. Saklofske. (Eds.), The SAGE Handbook of Personality Theory and Assessment: Vol. 2 - Personality Measurement and Testing. Los Angeles, CA: Sage.

Boyle, G. J., Stankov, L. \& Cattell, R. B. (1995). Measurement and statistical models in the study of personality and intelligence. In D. H. Saklofske \& M. Zeidner (Eds.), International Handbook of Personality and Intelligence (pp. 417-446). New York: Plenum. 
Brody, E. B. \& Brody, N. (1976). Intelligence: Nature, Determinants, and Consequences. New York: Academic.

Buchanan, R. D. (2010). Playing with Fire: The Controversial Career of Hans J. Eysenck. New York: Oxford University Press.

Cattell, H. E. P. \& Mead, A. D. (2008). The Sixteen Personality Factor Questionnaire (16PF). In G. J. Boyle, G. Matthews \& D. H. Saklofske. (Eds.), The SAGE Handbook of Personality Theory and Assessment: Vol. 2 - Personality Measurement and Testing (pp. 135-159). Los Angeles, CA: Sage.

Cattell, R. B. (1940). A culture-free intelligence test 1. Journal of Educational Psychology, 31, 161-179.

Cattell, R. B. (1962). The basis of recognition and interpretation of factors. Educational and Psychological Measurement, 22, 667-697.

Cattell, R. B. (1963). Theory of fluid and crystallized intelligence: a critical experiment. Journal of Educational Psychology, 54, 1-22.

Cattell, R. B. (1966a). (Ed.). Handbook of Multivariate Experimental Psychology. Chicago, IL: Rand McNally.

Cattell, R. B. (1966b). The scree test for the number of factors. Multivariate Behavioral Research, 1, 245-276.

Cattell, R. B. (1973). Personality and Mood by Questionnaire. San Francisco, CA: Jossey-Bass.

Cattell, R. B. (1978). The Scientific Use of Factor Analysis in Behavioral and Life Sciences. New York: Plenum. 
Cattell, R. B. (1984). Interview with Raymond B. Cattell. The Eugenics Bulletin (Spring-Summer). http://www.eugenics.net/papers/eb7.html (Retrieved 6 November, 2015)

Cattell, R. B. (1986). The 16PF personality structure and Dr. Eysenck. Journal of Social Behavior and Personality, 1, 153-160.

Cattell, R. B. (1987). Intelligence: Its Structure, Growth and Action. New York: North-Holland.

Cattell, R. B. (1995). The fallacy of five factors in the personality sphere. The Psychologist, May, 207-208.

Cattell, R. B. \& Johnson, R. C. (1986). (Ed.), Functional Psychological Testing: Principles and Instruments. New York: Brunner-Mazel.

Cattell, R. B. \& Warburton, F. W. (1967). Objective Personality and Motivation Tests: a Theoretical Introduction and Practical Compendium. Urbana, IL: University of Illinois Press.

Cronbach, L. J. (1957). The two disciplines of scientific psychology. American Psychologist, 12, 671-684.

Danziger, K. (1990). Constructing the Subject. Cambridge, UK: Cambridge University Press.

Deary, I. J. (2000). Looking Down on Human Intelligence: From Psychometrics to the Human Brain. Oxford: Oxford University Press.

de Moor, M. H. M., van den Berg, S. M., Verweij, K. J. H., Krueger, R. F., Luciano, M., Arias Vasquez, A., ... Boomsma, D. I. (2015). Meta-analysis of genome-wide 
association studies for neuroticism, and the polygenic association with major depressive disorder. JAMA Psychiatry, 72, 642-650.

Domingue, B. W., Belsky, D. W., Conley, D., Harris, K. M. \& Boardman, J. D. (2015). Polygenic influence on educational attainment: new evidence from the National Longitudinal Study of Adolescent to Adult Health. AERA Open, 1, 1-13.

Eysenck, H. J. (1952). The effects of psychotherapy: an evaluation. Journal of Consulting Psychology, 16, 319-324.

Eysenck, H. J. (1954). The science of personality - nomothetic. Psychological Review, 61, 339-342.

Eysenck, H. (1960). Handbook of Abnormal Psychology. London: Pitman.

Eysenck, H. (1967a). Intelligence assessment: A theoretical and experimental approach. British Journal of Educational Psychology, 37, 81-98.

Eysenck, H. J. (1967b). The Biological Basis of Personality. Springfield, IL: Thomas.

Eysenck, H. J. (1971). The IQ Argument: Race, Intelligence and Education. New York: Library Press.

Eysenck, H. J. (1973). The Measurement of Intelligence. Lancaster, UK: Medical \& Technical Publications.

Eysenck, H. J. (1979). The Structure and Measurement of Intelligence. New York: Springer-Verlag.

Eysenck, H. J. (1982). A Model for Intelligence. Berlin, Germany: Springer-Verlag. Eysenck, H. J. (1984). Cattell and the theory of personality. Multivariate Behavioral Research, 19, 323-336. 
Eysenck, H. J. (1985). Review of Raymond B. Cattell's (1983). Structured Personality-Learning Theory: A Wholistic Multivariate Research Approach. New York: Praeger.

Eysenck, H. J. (1986). Consensus and controversy: two types of science. In S. Modgil, \& C. Modgil. (1986). (Eds.), Hans Eysenck: Consensus and Controversy. Philadelphia, PA: Falmer Press.

Eysenck, H. J. (1987). Anomalous phenomena and orthodox science. Behavioral and Brain Sciences, 10, 584-585.

Eysenck, H. J. (1991a). Smoking, Personality and Stress: Psychosocial Factors in the Prevention of Cancer and Coronary Heart Disease. New York: SpringerVerlag.

Eysenck, H. J. (1991b). Reply to the criticisms of the Grossarth-Maticek studies. Psychological Inquiry, 2, 297-323.

Eysenck, H. J. (1992a). Four ways five factors are not basic. Personality and Individual Differences, 13, 667-673.

Eysenck, H. J. (1992b). The definition and measurement of psychoticism. Personality and Individual Differences, 13, 757-785.

Eysenck, H. J. (1993). Reply to van der Ploeg, Vetter, and Kleijn. Psychological Inquiry, 4, 70-73.

Eysenck, H. J. (1997a). Personality and experimental psychology: the unification of psychology and the possibility of a paradigm. Journal of Personality and Social Psychology, 73, 1224-1237. 
Eysenck, H. J. (1997b). Rebel with a Cause: The Autobiography of Hans Eysenck ( $2^{\text {nd }}$ rev. edn.). New Brunswick, NJ: Transaction Publishers.

Eysenck, H. J. (1998). Intelligence: A New Look. New Brunswick, NJ: Transaction Publishers.

Eysenck, H. J. \& Eysenck, M. W. (1985). Personality and Individual Differences: A Natural Science approach. New York: Plenum.

Eysenck, H. J. \& Nias, D. K. B. (1982). Astrology: Science or Superstition? London: Temple Smith.

Eysenck, M. W. (2016). Hans Eysenck: an evaluation of his career. Personality and Individual Differences, in press.

Eysenck, S. B. G., Eysenck, H. J. \& Barrett, P. (1985). A revised version of the psychoticism scale. Personality and Individual Differences, 6, 21-29.

Eysenck, S. B. G., Garcia-Sevilla, L., Torrubia, R., Avila, C. \& Ortet, G. (1992). Versió catalana de l'EPQ per a adults: un instrument per a la mesura de la personalitat [Catalan version of the EPQ for adults: an instrument to measure personality]. Annals de Medicina, 9, 223-230.

Furneaux, W. D. (1960). Intellectual abilities and problem solving behaviour. In H. J. Eysenck (Ed.), Handbook of Abnormal Psychology (pp. 167-192). New York: Basic Books.

Furnham, A., Eysenck, S. B. G. \& Saklofske, D. H. (2008). The Eysenck personality measures: fifty years of scale development. In G. J. Boyle, G. Matthews \& D. H. Saklofske. (Eds.), The SAGE Handbook of Personality Theory and Assessment: Vol. 2 - Personality Measurement and Testing (pp. 199-218). Los 
Angeles, CA: Sage.

Goldberg, L. (1968). Explorer on the run. Contemporary Psychology, 13, 617-619.

Goldberg, L. R. (1993). The structure of phenotypic personality traits. American

Psychologist 48, 26-34.

Gorsuch, R. L. (1997). Professor Gorsuch's letter to the APF: Raymond Bernard

Cattell. http://www.stthomasu.ca/ jgillis/awalifgor.htm (Retrieved 7

December, 2015)

Gray, J. (1997). Obituary: Hans Jürgen Eysenck (1916-97). Nature, 389, 974.

Haggbloom, S. J., Warnick, R., Warnick, J. E., Jones, V. K., Yarbrough, G. L.,

Russell, T. M., ... Monte, E. (2002). The 100 most eminent psychologists of the 20th century. Review of General Psychology, 6, 139-152.

Hebb, D. O. (1949). The Organization of Behavior: A Neuropsychological Theory. New York: Wiley.

Hendrickson, D. E. \& Hendrickson, A. E. (1980). The biological basis of individual differences. Personality and Individual Differences, 1, 3-33.

Hoh, J. \& Ott, J. (2003). Mathematical multi-locus approaches to localizing complex human trait genes. Nature Reviews Genetics, 4, 701-709.

Horn, J. L. (2001). Raymond Bernard Cattell (1905-1998). American Psychologist, 56, 71-72.

Horn, J. L. \& Cattell, R. B. (1966). Refinement and test of the theory of fluid and crystallized general intelligence. Journal of Educational Psychology, 57, 253-270.

Ibáñez, M. I., Ortet, G. \& Moro, M. (2000). Sesgo y consistencia interna de la escala revisada de psicoticismo: implicaciones conceptuales [Biases and internal 
consistency of the revised Psychoticism scale: conceptual implications].

Revista Española de Motivación y Emoción, 1, 37-44.

Jensen, A. R. (1982). Reaction time and psychometric $g$. In H. J. Eysenck (Ed.), A Model for Intelligence (pp. 93-132). Heidelberg, Germany: Springer-Verlag.

Klein, R. J., Zeiss, C., Chew, E. Y., Tsai, J. Y., Sackler, R. S., Haynes, C., ... Hoh, J. (2005). Complement factor $\mathrm{H}$ polymorphism in age-related macular degeneration. Science, 308, 385-389.

Kline, P. (1972). Fact and Fantasy in Freudian theory. London: Methuen.

Kline, P. (1997). Commentary on Michell, quantitative science and the definition of measurement in psychology. British Journal of Psychology, 88, 358-387.

Krug, S. E. (2008). The assessment of clinical disorders within Raymond Cattell's personality model. In G. J. Boyle, G. Matthews \& D. H. Saklofske. (Eds.), The SAGE Handbook of Personality Theory and Assessment: Vol. 2 - Personality Measurement and Testing (pp. 646-662). Los Angeles, CA: Sage.

Krug, S. E., \& Johns, E. F. (1986). A large scale cross-validation of second-order personality structure defined by the 16PF. Psychological Reports, 59, 683-693.

Lamiell, J. T. (1997). Individuals and the differences between them. In R. Hogan, J. Johnson \& S. Briggs (Eds.), Handbook of Personality Psychology (pp. 117141). San Diego, CA: Academic.

Lotz, M. (2008). Beyondism: The Thinking of Raymond Bernard Cattell (1905-1998) on Religion, and his Religious Thought. Masters Dissertation, University of South Africa, Pretoria, South Africa. http://uir.unisa.ac.za/handle/10500/2688 (Retrieved 9 November, 2015) 
Marqués, M.J., Ibáñez, M.I., Ruipérez, M.A., Moya, J. \& Ortet, G. (2005). The SelfRegulation Inventory (SRI): psychometric properties of a health related coping measure. Personality and Individual Differences, 39, 1043-1054.

Mershon, B. \& Gorsuch, R. L. (1988). Number of factors in the personality sphere: does increase in factors increase predictability of real-life criteria? Journal of Personality and Social Psychology, 55, 675-680.

Matthews, G., Zeidner, M. \& Roberts, R. D. (2004). Emotional Intelligence: Science and Myth. Cambridge, MA: MIT Press.

Michell, J. (2009). The psychometricians' fallacy: too clever by half? British Journal of Mathematical and Statistical Psychology, 62, 41-55.

Nesselroade, J. R. \& Cattell, R. B. (1988). (Eds.), Handbook of Multivariate Experimental Psychology ( $2^{\text {nd }}$ rev. edn.). New York: Plenum.

Ortet, G. Ibáñez, M.I., Moro, M., Silva, F. \& Boyle, G.J. (1999). Psychometric appraisal of Eysenck’s revised Psychoticism scale: a cross-cultural study. Personality and Individual Differences, 27, 1209-1219.

Petrides, K. V., Mikolajczak, M., Mavroveli, S., Sánchez-Ruiz, M-J., Furnham, A. \& Pérez-González, J-C. (2016). Recent developments in trait emotional intelligence research. Emotion Review, in press.

Petrides, K. V., Pita, R. \& Kokkinaki, F. (2007). The location of trait emotional intelligence in personality factor space. British Journal of Psychology, 98, 273289.

Piekkola, B. (2011). Traits across cultures: a neo-Allportian perspective. Journal of Theoretical and Philosophical Psychology, 31, 2-24. 
Plomin, R. \& Deary, I. J. (2015). Genetics and intelligence differences: five special findings. Molecular Psychiatry, 20, 90-108.

Rietveld C. A., Medland S. E., Derringer J., Yang J., Esko T., Martin N. G., ... Koellinger, P. D. (2013). GWAS of 126,559 individuals identifies genetic variants associated with educational attainment. Science, 340, 1467-1471.

Rietveld C. A., Conley D., Eriksson N., Esko T., Medland S. E., Vinkhuyzen A. A. E., ... the Social Science Genetics Association Consortium. (2014). Replicability and robustness of genome-wide-association studies for behavioral traits. Psychological Science, 25, 1975-1986.

Risch, N. \& Merikangas, K. (1996). The future of genetic studies of complex human diseases. Science, 273, 1516-1517.

Roberts, R. \& Stankov, L. (1999) Individual differences in speed of mental processing and human cognitive abilities: towards a taxonomic model. Learning and Individual Differences, 11, 1-120.

Saucier, G. (2008). Measures of the personality factors found recurrently in human lexicons. In G. J. Boyle, G. Matthews \& D. H. Saklofske. (Eds.), The SAGE Handbook of Personality Theory and Assessment: Vol. 2 - Personality Measurement and Testing (pp. 29-54). Los Angeles, CA: Sage.

Schneider, W. J. \& McGrew, K. S. (2012). The Cattell-Horn-Carroll model of intelligence. In D. Flanagan \& P. Harrison (Eds.), Contemporary Intellectual Assessment: Theories, Tests, and Issues ( ${ }^{\text {rd }}$ ed., pp. 99-144). New York: Guilford. 
Schuerger, J. M. (2008). The Objective-Analytic Test Battery. In G. J. Boyle, G. Matthews \& D. H. Saklofske. (Eds.), The SAGE Handbook of Personality Theory and Assessment: Vol. 2 - Personality Measurement and Testing (pp. 529-546). Los Angeles, CA: Sage.

Sheldrake, R. (2013). Setting science free from materialism. Journal of Science and Healing, 9, 211-218.

Snygg, D. (1955). Scientific method in psychology. Journal of General Psychology, 52, 189-196.

Stankov, L. (2013). Noncognitive predictors of intelligence and academic achievement: an important role of confidence. Personality and Individual Differences, 55, 727-732.

Stankov, L., Boyle, G. J. \& Cattell, R. B. (1995). Models and paradigms in personality and intelligence research. In D. H. Saklofske \& M. Zeidner (Eds.), International Handbook of Personality and Intelligence (pp. 15-43). New York: Plenum.

Stankov, L., Danthiir, V., Williams, L., Pallier, G., Roberts, R. \& Gordon, E. (2006). Intelligence and the tuning-in of brain networks. Learning and Individual Differences, 16, 116-146.

Stern, W. (1911). Differentielle psychologie in ihren methodischen grundlagen. Leipzig, Germany: Barth.

Sternberg, R. J., Forsythe, G. B., Hedlund, J., Horvath, J. A., Wagner, R. K., Williams, W. M., ...Grigorenko, E. L. (2000). Practical Intelligence in Everyday Life. Cambridge: Cambridge University Press. 
van den Berg, S. M., de Moor, M. H. M., McGue, M., Pettersson, E., Terracciano, A., Verweij, K. J. H., ... Boomsma, D. I. (2014). Harmonization of neuroticism and extraversion phenotypes across inventories and cohorts in the Genetics of Personality Consortium: an application of Item Response Theory. Behavior Genetics, 44, 295-313.

van den Berg, S. M., de Moor, M. H. M., Verweij, K. J. H., Krueger, R. F., Luciano, M., Arias Vasquez, A., ... Milaneschi, Y. (2015). Meta-analysis of genomewide association studies for extraversion: findings from the Genetics of Personality Consortium. Behavior Genetics. Published online: 11 September 2015. http://www.tweelingenregister.org/nederlands/verslaggeving/NTRpublicaties_2015/Berg_BG_2015_epub.pdf (Retrieved 7 December, 2015) van Kampen, D. (2009). Personality and psychopathology: a theory-based revision of Eysenck’s PEN model. Clinical Practice and Epidemiology in Mental Health, 5, 9-21.

Whitehead, A. N. (2011). Science and the Modern World. New York: Cambridge University Press. (Originally published in 1925). 